Corrigendum

\title{
Corrigendum to "Novel Hybrid Gels Made of High and Low Molecular Weight Hyaluronic Acid Induce Proliferation and Reduce Inflammation in an Osteoarthritis In Vitro Model Based on Human Synoviocytes and Chondrocytes"
}

\author{
Antonietta Stellavato $\left(\mathbb{D},{ }^{1}\right.$ Valentina Vassallo $(\mathbb{D}),{ }^{1}$ Annalisa La Gatta $\left(\mathbb{D},{ }^{1}\right.$ \\ Anna Virginia Adriana Pirozzi $\mathbb{D}^{1},{ }^{1}$ Mario De Rosa, ${ }^{1}$ Giovanni Balato, ${ }^{2}$ Alessio D'Addona, ${ }^{2}$ \\ Virginia Tirino $\mathbb{D}^{1}{ }^{1}$ Carlo Ruosi, ${ }^{2}$ and Chiara Schiraldi $\mathbb{D}^{1}$ \\ ${ }^{1}$ Department of Experimental Medicine, Section of Biotechnology, Medical Histology and Molecular Biology, University of Campania \\ "Luigi Vanvitelli", Naples, Italy \\ ${ }^{2}$ School of Medicine and Surgery "Federico II" of Naples, Department of Public Health, A.O.U. Federico II of Naples, Via S. Pansini, \\ 80131Naples, Italy
}

Correspondence should be addressed to Antonietta Stellavato; antonietta.stellavato@unicampania.it and Chiara Schiraldi; chiara.schiraldi@unicampania.it

Received 30 June 2020; Accepted 1 July 2020; Published 25 July 2020

Copyright (C) 2020 Antonietta Stellavato et al. This is an open access article distributed under the Creative Commons Attribution License, which permits unrestricted use, distribution, and reproduction in any medium, provided the original work is properly cited.

In the article titled "Novel Hybrid Gels Made of High and Low Molecular Weight Hyaluronic Acid Induce Proliferation and Reduce Inflammation in an Osteoarthritis In Vitro Model Based on Human Synoviocytes and Chondrocytes" [1], there was an error in Figure 6. In the part of Figure 6(a), "HCC $-24 \mathrm{~h}$ " is incorrect. The corrected figure is shown below, and is listed as Figure 1: 

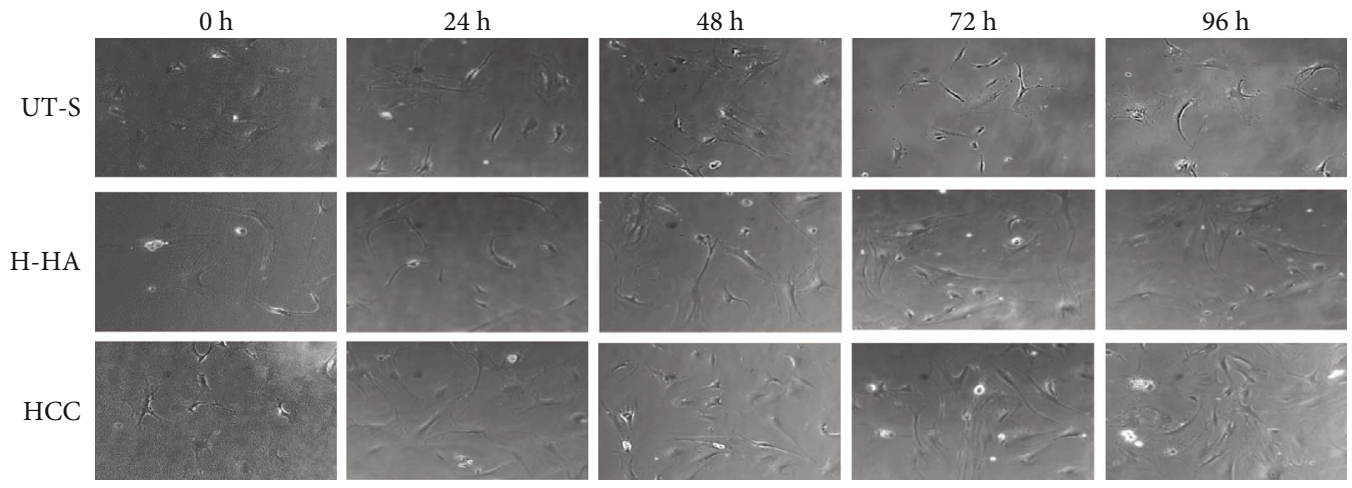

(a)

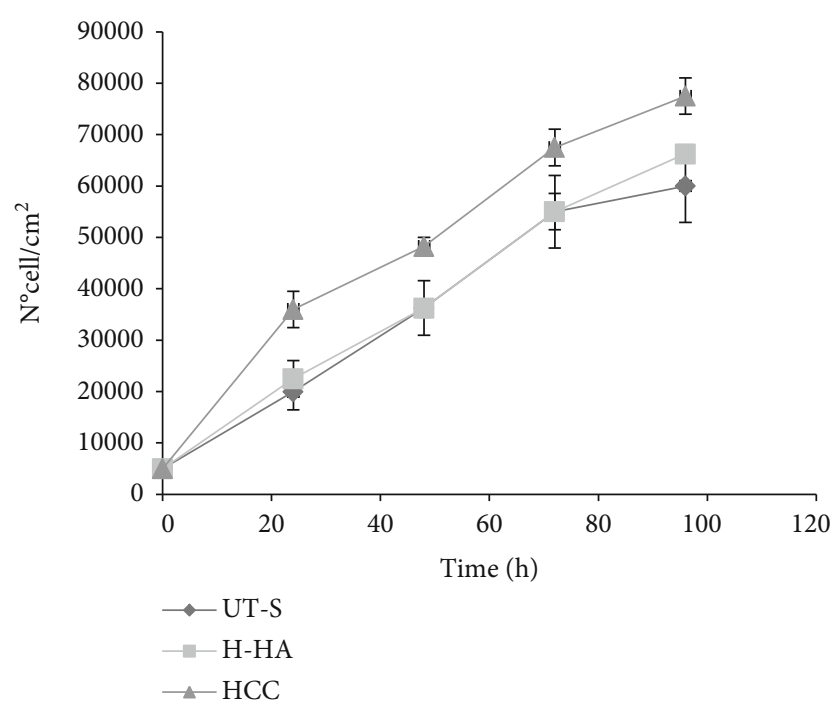

(b)

Figure 1: Human synoviocytes proliferation assay. (a) Pictures of cells at experimental times: 24, 48, 72 , and 96 h; the proliferative properties of HCC were compared to the single H-HA and untreated synoviocytes (UT-S). (b) Cell growth curves were obtained through the Image-Pro Plus 1.5 software (Media Cybernetics).

\section{References}

[1] A. Stellavato, V. Vassallo, A. La Gatta et al., "Novel hybrid gels made of high and low molecular weight hyaluronic acid induce proliferation and reduce inflammation in an osteoarthritis in vitro model based on human synoviocytes and chondrocytes," BioMed Research International, vol. 2019, Article ID 4328219, 13 pages, 2019. 